\title{
Potências da memória: arquivo e testemunho na arte contemporânea
}

\author{
Rafaela Alves Fernandes ${ }^{1}$ \\ DOI 10.20396/eha.vil4.3376
}

Seguir os rastros daquilo que restou

No célebre Manifesto Futurista, escrito em 1908, Filippo Marinetti² conclama seus contemporâneos a arrombarem as misteriosas portas do impossível e não mais olharem para trás. Num discurso crítico aos museus e às instituições representativas do passado, ele interroga: "Quereis, pois, desperdiçar todas as vossas melhores forças nessa eterna e inútil admiração do passado, da qual saís fatalmente exaustos, diminuídos e espezinhados?”. Anos mais tarde, em 1931, no texto 0 problema dos museus, Paul Valéry interpreta o museu como um reduto de visões mortas, uma herança esmagadora que reúne a vida em seu estado de paralisia.

Énesse contexto que muitos artistas ecríticos modernos sevoltaram contra o passado eas suas instituições representativas, como museus e bibliotecas, num gesto de recusa à sociedade burguesa e ao regime de autonomia da arte. Essa visão homogênea da história e a crença na experiência do progresso levaram a modernidade a uma cesura do tempo. Nos termos de ]ürgen Habermas3, "uma vez que o mundo novo, o mundo moderno, se distingue do velho pelo fato de que se abre ao futuro, o início de uma época histórica repete-se e reproduz-se a cada momento do presente, o qual gera o novo a partir de si". Isto é, a recusa dos modelos de outrora, fez com que a modernidade extraísse de si mesma os seus critérios de orientação e entrasse num processo de autofagia até transformar-se na própria tradição, até que se tornasse ruína. Essa primazia pelo instante, já constatada nos escritos do poeta ${ }^{4}$, em que "a Modernidade é o transitório, o efêmero, o contingente, é a metade da arte, sendo a outra metade o eterno e o imutável", sofreu um significativo abalo após a Segunda Guerra Mundial, ao passo que o presente já não abrigava a utopia do novo, mas, pelo contrário, apenas os traumas e as violências do passado.

\footnotetext{
1 Mestranda em Filosofia (Estética) pela FFLCH - Universidade de São Paulo, bacharela em História da Arte pela Universidade Federal de São Paulo (2017) e Licenciada em Artes Cênicas pela Faculdade Paulista de Artes (2010). Atualmente integra o grupo de estudos em Estética Contemporânea do Departamento de Filosofia da Universidade de São Paulo. É professora titular de Arte no ensino fundamental e médio pelas secretarias estadual e municipal de educação de São Paulo. E-mail: rafa_a_fernandes@hotmail.com

2 1996, p. 292

32000 , p. 11.

4 BAUDELAIRE, 1996, p. 25
} 
Após o fim da Segunda Guerra Mundial, verifica-se a recorrência de dispositivos de memória na produção de vários artistas que convocam o passado a fim de reelaborá-lo, seja na forma de testemunhos ou de arquivos, conceitos estes que nos interessam particularmente e que serão desenvolvidos mais adiante. Esta persistência de retorno ao passado apresenta-se como o sintoma de uma época que, no intuito de compreender o presente, escava memórias e reescreve a história a partir de suas ruínas e de seus fragmentos. De acordo com Andreas Huyssen, o anseio nostálgico do passado é uma espécie de utopia às avessas, pois na medida em que a modernidade e suas projeções utópicas foram se exaurindo, só restava manter fixos os olhos no passado, tornando-se improvável imaginar futuros alternativos.

É preciso, ainda, lembrar que a falência das utopias, das narrativas e de certo ideário vanguardista, indissociável de uma determinada concepção de temporalidade, coincide com as teorias sobre o epílogo da arte, da história e da história da arte, teorizado por autores como Francis Fukuyama, Jean-François Lyotard, Gianni Vattimo, Hans Belting e Arthur C. Danto. Contudo, se o retorno ao passado representa um sintoma de perda de certa capacidade de imaginar e inventar o futuro, qual o conceito de memória adotado? Afinal, o que é uma memória?

Com frequência pensamos a memória como um livro de história que narra apogeus e derrocadas, descobertas e exploração de territórios, sob um único ponto de vista. Walter Benjamin propõe exatamente o contrário quando diz que é necessário "escovar a história à contrapelo". No tocante à memória, isso significa escavar e recordar aquilo que foi deliberadamente esquecido em favor da escrita de uma narrativa que beneficiou apenas as classes dominantes de uma dada sociedade. Talvez, uma forma mais apropriada seria pensar os fragmentos da memória, não enquanto fato objetivo que representaria uma mera ilusão teórica do historiador, mas como fato em movimento, isto é, que relembre o passado e assuma uma imagem no presente, tal como determinadas reminiscências relampejam no instante de um perigo 5 .

A exigência de memória em Benjamin, para quem no conceito de imagem dialética, o ato de rememorar tem o poder de restituir as potências de uma experiência do passado no agora, vinculase a uma legibilidade e visibilidade que certas imagens adquirem no presente. "Porque é irrecuperável toda imagem do passado que ameaça desaparecer com todo presente que não se reconheceu como presente intencionado nela". Num outro texto exemplar sobre o assunto, Escavando e recor- 
dando, Benjamin" alerta sobre o fato de que "o trabalho da verdadeira recordação [Erinnerung] deve ser menos o de um relatório, e mais o da indicação exata do lugar onde o investigador se apoderou dessas recordações", seria preciso, portanto, seguir os rastros daquilo que restou.

Desse modo, tratar de um regime estético da memória implica admitir que o passado nem sempre se apresenta na forma de presenças e vestígios explícitos, mas também de invisibilidades ou até mesmo de desaparecimentos. Em 2011, o filósofo e historiador da arte Georges Didi-Huberman visitou Auschwitz-Birkenau com uma câmera fotográfica em punho e registrou imagens que nos convidam a olhar os vestígios da tortura de um ponto de vista arqueológico, isto é, "comparar o que vemos no presente, o que sobreviveu, com o que sabemos ter desaparecido" ${ }^{8}$, pois apesar da aniquilação da vida e de todos os seus restos, convém interrogar as camadas de tempo soterradas, os modos de construção da memória, as possibilidades de transmissão do conhecimento sensível e, sobretudo, o nosso próprio olhar sobre as coisas, visíveis e invisíveis. Em tom confessional, Didi-Huberman" escreveu sobre tal experiência: "Olhei as árvores como alguém que interroga testemunhas mudas".

Doravante, convém discorrermos a propósito dos dois conceitos - testemunho e arquivo que serão chaves de leitura das obras aqui brevemente analisadas e que nos ajudarão a pensar sobre as formas e procedimentos adotados por artistas que evocam o passado para reescrever o presente. Em O que resta de Auschwitz, ao referir-se aos sobreviventes ${ }^{10}$ do holocausto, Giorgio Agamben expõe sua interpretação paradoxal da noção de testemunho e nos alerta quanto a algo similar a uma impossibilidade de testemunhar:

A testemunha comumente testemunha a favor da verdade e da justiça, e delas a sua palavra extrai consistência e plenitude. Nesse caso, porém, o testemunho vale essencialmente por aquilo que nele falta; contém, no seu centro, algo intestemunhável, que destitui a autoridade dos sobreviventes. As "verdadeiras" testemunhas, as "testemunhas integrais" são as que não testemunharam, nem teriam podido fazê-lo. São os que "tocaram o fundo", os muçulmanos, os submersos. Os sobreviventes, como pseudotestemunhas, falam em seu lugar, por delegação: testemunham sobre um testemunho que falta. Contudo, falar de uma delegação, no caso, não tem sentido algum: os submersos nada têm a dizer, nem têm instruções ou memórias a transmitir. Não têm "história", nem "rosto" e, menos ainda, "pensamento". Quem assume para si o ônus de testemunhar por eles, sabe que deve testemunhar pela impossibilidade de testemunhar. Isso, porém, altera de modo definitivo o

\footnotetext{
7 2000, p. 239.

8 DIDI-HUBERMAN, 2017, p. 41.

9 2017, p. 71.

10 Nos termos de Agamben, "o sobrevivente tem a vocação da memória, não pode deixar de recordar". (2008, p. 36).
} 
valor do testemunho, obrigando a buscar o sentido em uma zona imprevista. ${ }^{11}$

O caráter paradoxal do testemunho consiste em afirmar que o testemunho integral seria feito somente por aqueles que já não têm voz, pois morreram, mas, ao mesmo tempo, o testemunho dos sobreviventes é uma tentativa de narrar o inenarrável, aquilo que não pode ser esquecido, principalmente quando o passado de que se quer esquecer permanece ainda no agora. Adorno ${ }^{12}$, numa passagem elucidativa sobre a recusa do passado na Alemanha pós-Segunda Guerra, afirma que "o gesto de tudo esquecer e perdoar, privativo de quem sofreu a injustiça, acaba advindo dos partidários daqueles que praticaram a injustiça" ou que "o esquecimento do nazismo pode ser explicado muito mais a partir da situação social geral do que a partir da psicopatologia"13. Para Adorno, o passado só estará plenamente elaborado quando as causas que o engendraram tiverem sido superadas.

Evidentemente que Agamben não estaria se referindo apenas à experiência do holocausto quando ele fala sobre o testemunho, Auschwitz é uma alegoria do limite, do limite da vida nua ${ }^{14}$ que não cessa de se reproduzir em diversos contextos sociais. Nessa direção, consideremos dois artistas que pertencem ao corpus desta pesquisa e que trabalham a partir da noção de testemunho, inscrevendo suas obras no território da política ao proporem uma discussão pública em torno de problemas associados à memória histórica: Doris Salcedo (1958) e Christian Boltanski (1944).

Doris Salcedo, artista colombiana, dá voz a vítimas da violência política durante a guerra civil que assolou seu país natal, assim como a refugiados, imigrantes e vítimas de tragédias individuais ou coletivas que sentiram na pele os abusos dos mecanismos de poder, a fim de dar legitimidade a determinados acontecimentos que não podem ser esquecidos.

Por meio de prolongadas pesquisas de campo e entrevistas com aqueles que sofreram algum tipo de violência ou perda, Salcedo ${ }^{15}$ produz obras que não são exatamente sobre uma experiência traumática particular, mas que se tornam constructos de uma memória maior e compartilhada

\footnotetext{
11 AGAMBEN, 2008, p. 43.

12 2010, p. 2.

13 2010, p. 4

14 A noção de "vida nua" em Agamben deriva da distinção entre zoé (o fato de viver comum a todos os seres vivos) e bios (vida qualificada, isto é, a maneira de viver própria de um indivíduo ou de um grupo), advinda dos gregos. Logo, para Agamben, a vida nua consistiria numa vida que não é nem zoé nem bios, ao contrário, é uma vida construída a partir da cesura entre a vida ética e política e a vida biológica. A esse respeito: "A fórmula singular 'gerada em vista do viver, existente em vista do viver bem' pode ser lida não somente como uma implicação da geração (ginoméne) no ser (oûsa), mas também como uma exclusão inclusiva (uma exceptio) da zoé na polis, quase como se a política fosse o lugar em que o viver deve se transformar em viver bem, e aquilo que deve ser politizado fosse desde sempre a vida nua. A vida nua tem na política ocidental este singular privilégio de ser aquilo sobre cuja exclusão se funda a cidade dos homens”. (ACAMBEN, 2002a, p. 15).

15 Entrevista concedida pela artista Doris Salcedo, disponível em <http://esferapublica.org/nfblog/doris-salcedo-el-buen-arte-es-politico/>. Acesso em: 15/07/2019.
} 
socialmente. Ela se define como uma "testemunha secundária" e defende que toda boa arte é fundamentalmente política, pois abre caminhos e espaços desconhecidos. Em suas obras há sempre um testemunho que visa mostrar as marcas deixadas pela violência, sobretudo nas pessoas que a sofreram, e transmiti-las ao espectador por meio de uma "contemplação silenciosa", como o silêncio do luto.

Como a arte pode apresentar a violência sem violência, isto é, sem exaltá-la ou torná-la inevitável? Como representar o irrepresentável, isto é, o horror, a violência? Estas questões são centrais no trabalho de Salcedo, pois se referem a um problema ético e a uma responsabilidade da qual o artista não pode escapar ao trabalhar com a memória, especialmente com as traumáticas. Para Salcedo, a arte está mais próxima do rito funerário que dignifica aquele que já não está mais presente, do que de qualquer forma de redenção estética da barbárie.

Em Palimpsesto (2017) [Figura1], obra criada para o Palácio de Cristal em Madrid, Doris Salcedo expõe os visitantes a um espaço vazio onde são alertados a caminharem com cuidado. No chão, escritos com água, há nomes de pessoas que morreram nos últimos anos no Mar Mediterrâneo em desesperadas travessias rumo à Europa. Já em Ação de duelo (2007), quase 24 mil velas foram acesas na Praça de Bolívar, em Bogotá, com a ajuda dos transeuntes, em resposta à morte dos deputados colombianos do Valle del Cauca, que haviam sido feitos reféns em 2002. Outra obra de forte impacto visual e político é a instalação Topografia da guerra (2003), que consistiu no agrupamento de 1550 cadeiras entre dois edifícios da cidade durante a $8^{\text {a }}$ Bienal Internacional de Istambul, em que a artista faz referência ao acúmulo de corpos de "vidas matáveis", às valas comuns de pessoas anônimas.

O artista francês Christian Boltanski, ao contrário de Doris Salcedo, não parte de testemunhos de pessoas, mas se interessa em extrair o potencial de testemunho dos objetos e das imagens que utiliza em suas obras. Segundo Didi-Huberman ${ }^{16}$, a grande astúcia de Boltanski é parecer que está sempre falando dele mesmo, o que seria uma armadilha reducionista, mas de fato ele fala somente dos outros confrontados à história. Nos termos do próprio artista, "todo trabalho artístico é uma maneira de honrar os mortos", uma forma de transmissão do saber e do não saber sobre os esquecidos da história. Logo, o que Boltanski almeja é dignificar as imagens e restitui-las para além do esquecimento.

Na Monumenta 2010, no Grand Palais de Paris, Boltanski criou uma instalação denominada 


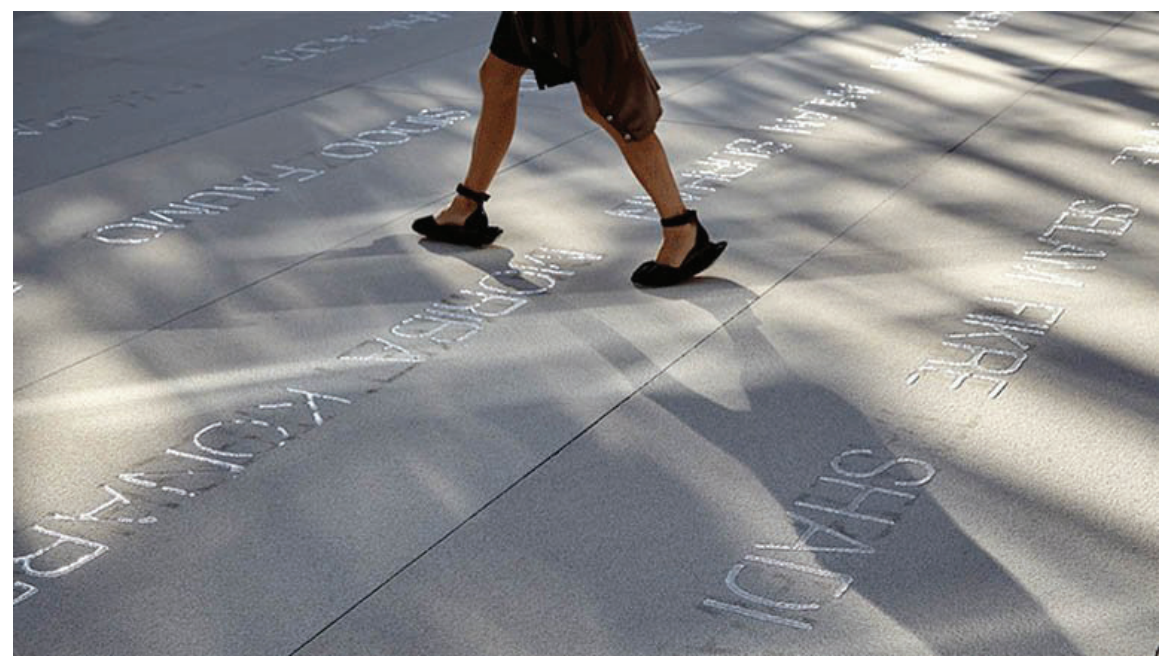

[Figura 01]

Doris Salcedo, Palimpsesto, 2017.

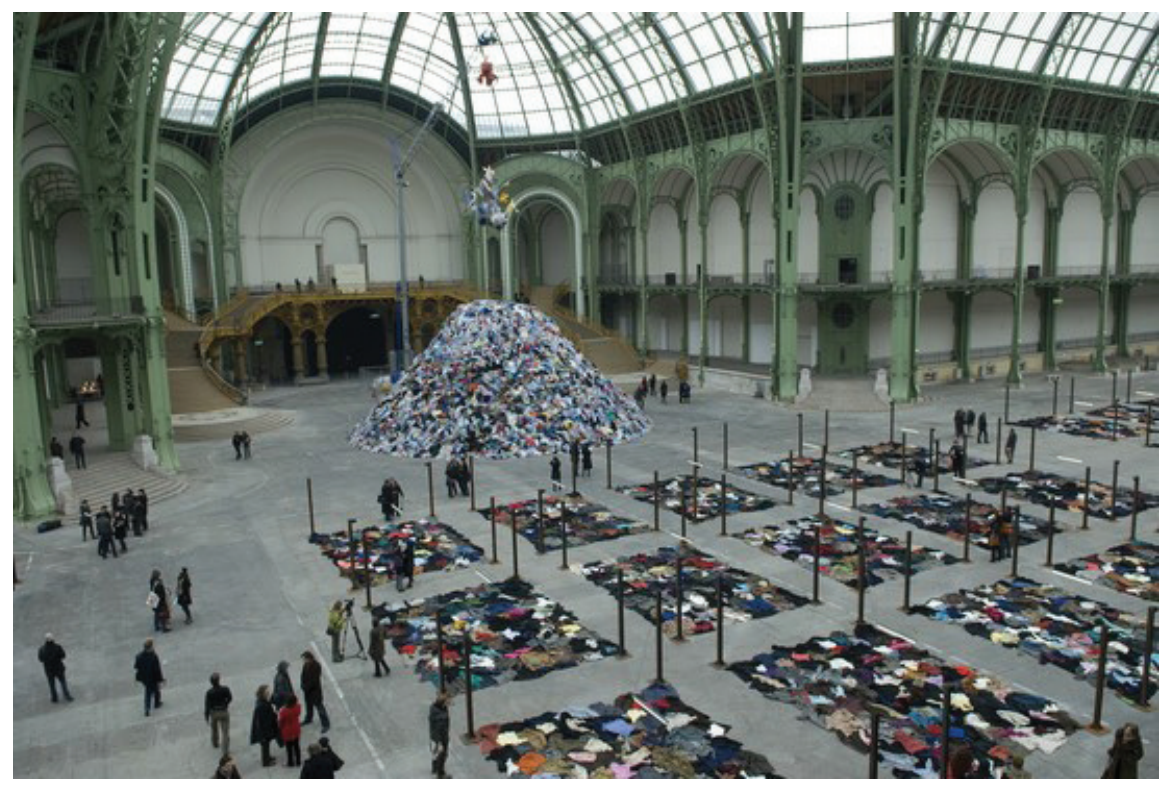

\section{[Figura 02]}

Christian Boltanski, Personnes, 2010.

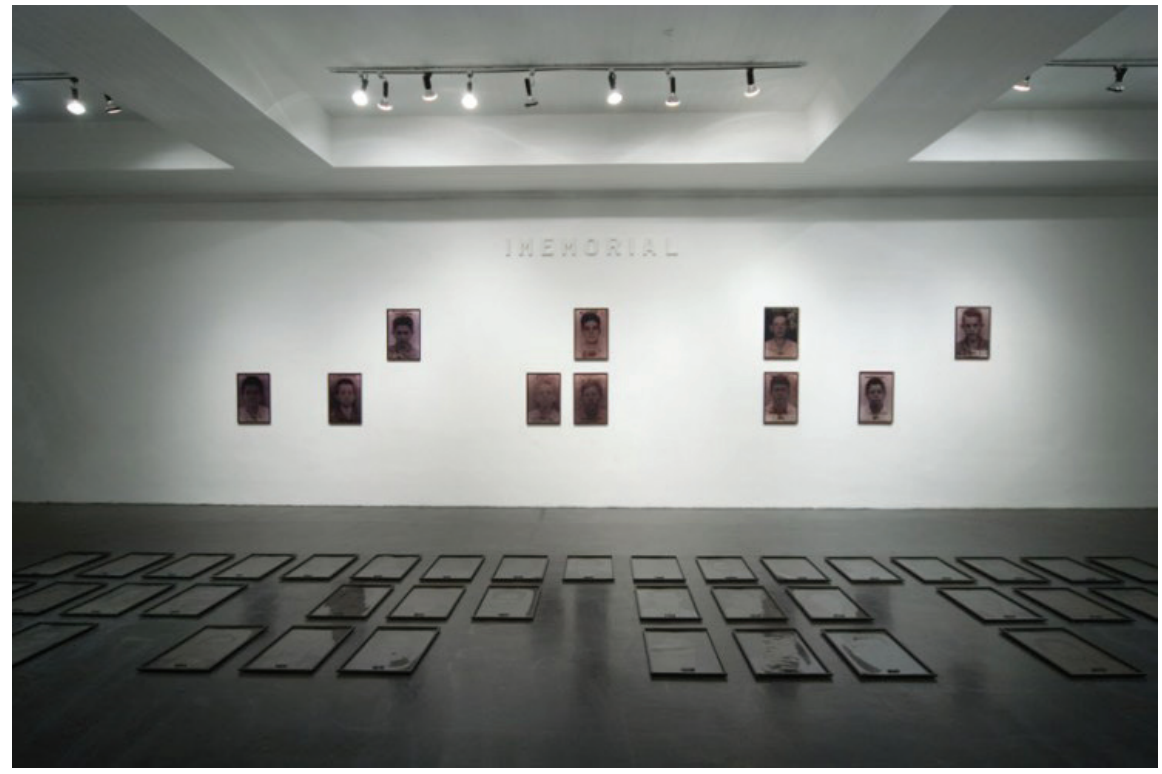

[Figura 03]

Rosangela Rennó, série Imemorial, 1994. 
Personnes [Figura 2], que pode ser traduzido tanto como "pessoas" quanto como "ninguéns". Tal aspecto é elucidativo quando nos confrontamos com a obra: uma pilha de roupas usadas e um grande guindaste que iça aleatoriamente algumas peças e após um tempo as deixa cair para, então, integrar novamente a pilha. No mesmo espaço, há roupas espalhadas pelo chão, organizadas em campos e separadas por corredores por onde o espectador é convidado a caminhar. Roupas que remetem a corpos ausentes, a presença constante da morte, a despersonalização a que os indivíduos são submetidos, aos campos de genocídio, às valas comuns. O próprio Boltanski afirma que "há uma direta relação entre uma peça de roupa, uma fotografia e um corpo, no qual alguém uma vez existiu, mas agora não mais"17.

Nas décadas de 80 e 90, Boltanski se dedicou a contar histórias que mereciam, mas não podiam ser contadas. É dessa época a construção de uma série de monumentos à memória das vítimas da guerra e do holocausto. Entretanto, como não pretendo aqui esgotar o assunto, destaco somente o projeto La Maison manquante, realizado em comemoração pela unificação das duas Alemanhas, em 1990. Boltanski identificou nas ruas de Berlim lacunas deixadas pela guerra, espaços que não foram reconstruídos, ruínas silenciosas. Ele, então, pesquisa documentos sobre os moradores das antigas casas e os expõe em vitrines. Nos muros das construções que restaram, o artista fixa placas com informações a respeito dos antigos moradores. Um gesto de resistência ao despedaçamento do tempo, ao desaparecimento dos vestígios de vidas, antes, condenadas ao esquecimento.

O testemunho possui no senso comum certo estatuto de verdade por concentrar-se na experiência vivida que é narrada a partir de lembranças. Contudo, nos trabalhos desses dois artistas apresentados - Doris Salcedo e Christian Boltanski - o que vemos não são discursos messiânicos em torno da verdade de um fato ocorrido, mas, como diria Agamben, as histórias que restaram ${ }^{18}$. O caráter ambíguo de suas obras reside no fato de não serem exatamente testemunhos pessoais, isto é, do próprio artista, mas das inúmeras barbáries cometidas pela cultura. Ambos os artistas restituem a dignidade de sujeitos, específicos ou anônimos, impossibilitados de narrarem suas histórias, na maioria dos casos, histórias de violência. É comum também em suas obras não haver fronteiras precisas entre ficção e realidade, uma vez que cada material apropriado ou intervenção nele feita configura-se como um gesto de linguagem do artista.

\footnotetext{
17 Entrevista a Tamar Garb. In: CARB, Tamar; SEMIN, Didier; KUSPIT, Donald. Christian Boltanski. Nova lorque: Phaidon, 1997, p. 19.

18 O conceito de resto é central no pensamento de Giorgio Agamben. Entretanto, nos deteremos apenas em enunciá-lo. "Significa, sim, que a palavra poética é aquela que se situa, de cada vez, na posição de resto, e pode, dessa maneira, dar testemunho. Os poetas - as testemunhas fundam a língua como o que resta, o que sobrevive em ato à possiblidade-ou à impossibilidade de falar" (ACAMBEN, 2008, p. 160).
} 
Em relação à noção de arquivo, mesmo longe de esgotar o assunto, apresentamos duas interpretações a seguir. Poderíamos definir o arquivo em função de sua tarefa básica de ordenar e preservar documentos de ou para uma dada cultura e, assim, servir à história. Entretanto, é preciso lembrar que a noção de arquivo foi inúmeras vezes expandida e reelaborada ao longo do século XX, a partir do questionamento de seu estatuto "factual" e de sua suposta neutralidade. Michel Foucault é um dos pensadores que, ao criticar os discursos oficiais e interrogar as narrativas institucionais, propõe uma revisão da maneira como entendemos a noção de documento e alerta quanto aos jogos de poder presentes nas ordens discursivas. O arquivo seria, segundo ele, marcado pela descontinuidade enquanto instrumento de formação e transformação dos enunciados. A tarefa do historiador, portanto, consistiria em reconhecer nos arquivos os sistemas que engendraram a construção dos discursos.

O arquivo é, de início, a lei do que pode ser dito, o sistema que rege o aparecimento dos enunciados como acontecimentos singulares. Mas o arquivo é, também, o que faz com que todas as coisas ditas não se acumulem indefinidamente em uma massa amorfa, não se inscrevam tampouco, em uma linearidade sem ruptura e não desapareçam ao simples acaso de acidentes externos, mas que se agrupem em figuras distintas, se componham umas com as outras segundo relações múltiplas, se mantenham ou se esfumem segundo regularidades específicas. ${ }^{19}$

Outro autor que contribuiu para o alargamento do conceito de arquivo é Jacques Derrida. Publicado em 1995 na França, Mal de arquivo: uma impressão freudiana, é fruto de uma conferência realizada em Londres no ano anterior e tornou-se um dos textos fundamentais na desconstrução do conceito clássico de arquivo. Expressamente, trata-se de um diálogo que Derrida estabelece com a teoria psicanalítica freudiana. Não por acaso, seu ponto de partida é a palavra "arquivo":

Não comecemos pelo começo nem mesmo pelo arquivo. Mas pela palavra "arquivo" - e pelo arquivo de uma palavra tão familiar. Arkhê lembremos, designa ao mesmo tempo o começo e o comando. Este nome coordena aparentemente dois princípios em um: o princípio da natureza ou da história - ali onde as coisas começam - princípio físico, histórico ou ontológico -, mas também o princípio da lei - ali onde os homens e os deuses comandam, ali onde se exerce a autoridade, a ordem social, nesse lugar a partir do qual a ordem é dada. ${ }^{20}$

"Origem" e "autoridade", portanto, seriam dois princípios que permeariam a noção de arqui- 
vo, e que, de acordo com Derrida, imporiam graves dificuldades à ideia de arquivamento no sentido clássico do conceito. Mas ele identifica que em todo e qualquer arquivo subsistiria uma tensão entre a preservação e a destruição, indissociável da pulsão de morte descrita por Freud. Esta constante tensão é o que ele denominou de "mal de arquivo". Para Derrida ${ }^{21}$, da pulsão de morte decorre o caráter lacunar e descontínuo do arquivo, necessariamente perpassado pelo esquecimento, visto que é a partir do esquecimento que os arquivos se redefinem e estabelecem novas relações discursivas: "A questão do arquivo não é, repetimos, uma questão do passado [...] Trata-se do futuro, a própria questão do futuro, a questão de uma resposta, de uma promessa e de uma responsabilidade para amanhã".

Para compor o nosso inventário - uma vez que intentamos ordenar as ideias por meio de um processo de arquivamento semelhante àquele de Derrida -, o trabalho da artista brasileira Rosangela Rennó (1962) é exemplar. Tal como a figura do trapeiro benjaminiano que coleciona toda sorte de objetos e empreende um trabalho de arqueologia do baixo e daquilo que foi descartado, Rennó se apropria de materiais de arquivos institucionais e vernaculares e cria seu próprio arquivo - como é o caso do projeto Arquivo universal -, ou seja, produz arquivos fictícios, problematiza a questão do arquivamento e trabalha a partir de procedimentos arquivais.

Na série Imemorial (1994) [Figura 3], a artista concebeu uma instalação com 50 fotografias provenientes do Arquivo Público de Brasília com retratos de trabalhadores que morreram no processo de construção da capital e símbolo do projeto de um país moderno para o Brasil. O arquivo morto reanimado por Rennó sussurra frases como: "isso aconteceu, isso pertence a uma história" e propõe ao público que reescreva a história e repense a ideia de uma identidade nacional redentora. Afinal, imagens fantasmáticas, vestígios de narrativas soterradas pela memória oficial, requerem a transformação de espectadores distraídos em debatedores envolvidos, considerando que fazer ressurgir imagens de um passado apagado é muito mais difícil do que se lembrar de coisas simplesmente esquecidas.

A partir desses trabalhos, conforme Rancière ${ }^{22}$, identificamos dois regimes de memória distintos entre si: "de um lado, o dos poderosos soberanos de outrora [...]; de outro, o do mundo contemporâneo, que não cessa, ao contrário de registrar o testemunho das existências mais comuns e dos acontecimentos mais banais". Assim, os artistas do corpus desta pesquisa parecem 
exercer uma função historiadora em suas poéticas, fazendo os testemunhos silenciados falarem ou extraindo outras narrativas dos arquivos empoeirados. Portanto, se vivemos em uma época de hipertrofia da memória, como sustenta Andreas Huyssen, é preciso empreender uma reflexão filosófica e estética acerca de suas formas de aparição e possíveis significações, algo análogo, talvez, ao que fez Nietzsche quanto ao excesso de história que ele identificou no final do século XIX.

\section{Referências bibliográficas}

ADORNO, Theodor. $\mathbf{O}$ que significa elaborar o passado. In: Educação e Emancipação. Rio de Janeiro: Paz e Terra, 2010, pp. 119-138.

ACAMBEN, Giorgio. Homo Sacer: o poder soberano e a vida nua I. Belo Horizonte: Ed. UFMG, 2002.

0 que resta de Auschwitz: o arquivo e a testemunha. São Paulo: Boitempo, 2008.

BAUDELAIRE, Charles. Sobre a modernidade. Rio de Janeiro: Paz e Terra, 1996.

BENJAMIN, Walter. Passagens. São Paulo, Imprensa Oficial do Estado de São Paulo/ Belo Horizonte: Ed. UFMG, 2009.

Magia e técnica, arte e política, ensaios sobre literatura e história da cultura. Obras Escolhidas V. 1, $7^{\text {a }}$ ed. São Paulo: Brasiliense, 1994.

O anjo da história. Belo Horizonte: Autêntica, 2012.

CHIPP, Herschel B. Teorias da arte moderna. $2^{\mathrm{a}}$ ed. São Paulo: Martins Fontes, 1996.

DERRIDA, Jacques. Mal de arquivo: uma impressão freudiana. Rio de Janeiro: Relume Dumará, 2001.

DIDI-HUBERMAN, Georges. Quando as imagens tomam posição. Belo Horizonte: Editora UFMG, 2017.

Cascas. São Paulo: Editora 34, 2017.

Remontagens do tempo sofrido. Belo Horizonte: Editora UFMG, 2018.

FOSTER, Hal. An archival impulse. October, Cambridge, n. 110, outono, 2004.

FABBRINI, Ricardo N. O fim das vanguardas: da modernidade à pós-modernidade.

FOUCAULT, Michel. A arqueologia do saber. $7^{\mathrm{a}}$ ed. Rio de Janeiro: Forense Universitária, 2008.

O corpo utópico, as heterotopias. São Paulo: N -1 Edições, 2013.

HABERMAS, Jurgen. 0 discurso filosófico da modernidade. São Paulo: Martins Fontes, 2000.

HUYSSEN, Andreas. Memórias do Modernismo. Rio de Janeiro: UFR], 1997.

Culturas do passado-presente: modernismos, artes visuais, políticas da memória. Rio de Janei-

ro: Contraponto: Museu de Arte do Rio, 2014.

RANCIĖRE, Jacques. Figuras da história. São Paulo: Editora Unesp, 2018.

ROSSI, Paolo. O passado, a memória e o esquecimento: seis ensaios da história das ideias. São Paulo, Editora da UNESP, 2010.

SELICMANN-SILVA, M. O local da diferença: Ensaios sobre memória, arte, literatura e tradução. São Paulo: Editora 34, 2005.

Antimonumentos: trabalho de memória e de resistência. Psicologia USP, vol. 27, número 1, p.

49-60, 2016.

VALÉRY, Paul. O problema dos museus. In: MAC Revista, N. 2. Dezembro/ 1993. 